\title{
Сверхдолгоживущие спиновые возбуждения в электронном двумерном газе \\ Дикман С.М.
}

ИФТТ РАН, Черноголовка, Московская область, 142432 Россия

DOI 10.34077/Semicond2019-196

Самым низко-энергетичным возбуждением в квантово-холловской системе при заполнении $v=2$ является чисто электронный 'спин-циклотронный экситон' (СЦЭ), который формируется 'спинперевернутым' электроном, возбужденным с нулевого на первый уровень Ландау и условной 'дыркой' вакансией, возникающей на нулевом уровне. Энергия такого экситона отделена сверху от более высокой магнетоплазменной моды на величину отрицательного кулоновского сдвига $\left(\Delta E_{\mathrm{C}} \sim 1 \mathrm{MB}\right)$, а снизу от основного состояния на величину щели $\omega_{\mathrm{c}}-\Delta E_{\mathrm{C}}-\epsilon_{\mathrm{Z}} \sim 5-7 \mathrm{MB}$ (см. Рис1). Пространственная дисперсия СЦЭ характеризуется плавным неглубоким минимумом при волновом векторе $q=q_{0} \sim 1 / l_{B}[1-2]$ $\left(l_{B}\right.$-магнитная длина). При низких температурах (фактически при $T<0.1 \mathrm{~K})$ СЦЭ может релаксировать (т.е. аннигилировать) только в случае испускания жестких акустических фононов [3]. Очень медленная релаксация объясняется главным образом тем, что, процесс испускания фонона/фононов затруднен из-за эффективно слабого электрон-фононного взаимодействия для

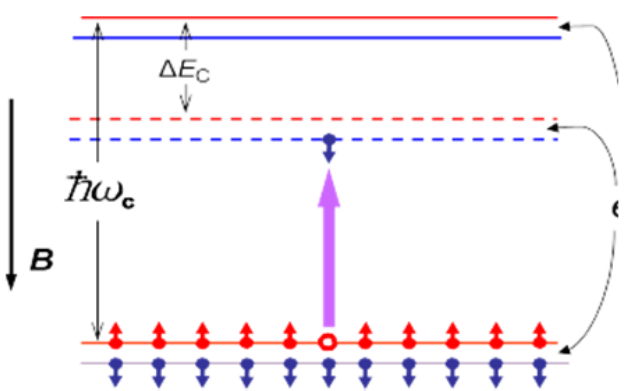

Рис1.- Схема возбуждения СЦЭ в квантово-холловской системе на основе GaAs/AlGaAs при v=2. $\triangle E C-$ кулоновский сдвиг. коротких значений длин волн, соответствующих энергии аннигиляции СЦЭ. Теоретическая оценка дает при нулевой температуре значение времени жизни в несколько миллисекунд. Экспериментально показано, что уже при температурах $T>0.4 \mathrm{~K}$ это время составляет 100 мкс [4-5], что, по-видимому, тоже является рекордным значением времени жизни для нелокализованных чисто электронных возбуждений, создаваемых в зоне проводимости. Плотный ансамбль СЦЭ с концентрацией, достигающей $10 \%$ от числа $N_{\phi}$ квантов магнитного потока, создается лазерной накачкой, соответствующей резонансной частоте возбуждения. Состояния ансамбля исследовались с помощью время-разрешающей техники фотоиндуцированного резонансного поглощения/отражения [4-5]. Внутри диапазона $0.4 \mathrm{~K}<T<1 \mathrm{~K}$ при заданной концентрации экситонов, $n=$ $N_{x} / N_{\phi}>5 \%$, наблюдалось резкое возрастание сигнала отражения для температур ниже некоторой пороговой величины $T_{0}=T(n)$ [5], что объясняется квантовым фазовым переходом экситонного ансамбля из неупорядоченного состояния в некоторое когерентное состояние, предположительно бозеэйнштейновский конденсат. Теория, в терминах так называемого `экситонного представления’ (см. [2-3]), описывает обе фазы в приближении невзаимодействующих СЦЭ, что дает возможность оценить энергию пространственной локализации СЦЭ, определяемую внешним случайным потенциалом (см. 'Supplementary Note 1' в [5]), и объяснить усиление примерно на порядок сигнала резонансного отражения при переходе в когерентную фазу. Вычисляется также отрицательная вириальная поправка к энергии СЦЭ (пропорциональная $n$ в рамках модели слабо неидеального газа), соответствующая эффективно аттрактивному взаимодействию СЦЭ с другими экситонами ансамбля [6]. Сравнение этой поправки с энергией локализации дает оценку критической концентрации перехода из некогерентной фазы в когерентную. Результаты находятся в согласии с экспериментальными данными.

[1] C. Kallin and B.I. Halperin, Phys. Rev. B 30, 5655 (1984).

[2] S. Dickmann and I.V. Kukushkin, Phys. Rev. B 71, 241310(R) (2005).

[3] S. Dickmann, Phys. Rev. Lett. 110, 166801 (2013).

[4] L.V. Kulik, A.V. Gorbunov, A.S. Zhuravlev, et al, Nature Sci. Rep. 5, 10354 (2015).

[5] L.V. Kulik, A.S. Zhuravlev, S. Dickmann, et al, Nature Comm. 7, 13499 (2016).

[6] S. Dickmann, Lithuanian Journal of Physics (2019), in press. 